\title{
VALUING WATER SUPPLY SERVICE IMPROVEMENTS IN ADDIS ABABA ${ }^{1}$
}

\author{
Kinfe G.Egziabher ${ }^{2}$ and Berhanu Adnew ${ }^{3}$
}

\begin{abstract}
In many cities of developing countries, such as Addis Ababa, water supply service is poor. At the moment, Addis Ababa city which accounts for over a quarter of the nations urban population is facing unreliable and inadequate supply of water and sanitation services. The paper raises crucial issues regarding the necessity to better understand the demand for improved water supply service in the absence of market and tries to link in relation to customers' participation in the provision of improved water supply service. In an attempt to examine the determinants of the value of improved water service and to establish how much consumers are willing to pay, we use a contingent valuation method (CVM). The tobit model shows socio-economic and demographic variables such as Income of the household, sex of the respondent dummy (female = 1), Family size, education (both secondary and tertiary level), households' year of stay, households not using tank as a storage, wealth of a household, employment status of the respondent dummy (employed = 1) , households satisfaction with the existing service dummy (unsatisfied=1), and location of the study site (Addis Ketema) are significant variables that explain the willingness to pay. The mean willingness to pay (WTP) values are 15.34 and 20.20 cents per bucket (a 20 liter container) above the exiting average tariff of 7.14 cents per bucket as calculated from the tobit and probit model, respectively. The empirical evidence is an important input for strategic planning to ensure that improvements proposed potentially improve cost recovery initiative and increase the level of customer satisfaction.
\end{abstract}

\footnotetext{
${ }^{1}$ The final version of this article was submitted in October 2008

${ }_{3}^{2}$ Lecturer, Mekelle University in the Department of Natural Resource Economics and Management Ethiopian Economic Policy Research Institute (EEPRI), Agriculture and Rural Development Division Head
} 


\section{Introduction}

The world faces severe and growing challenges to sustain water quality and meet the rapidly growing demand for water resources. In 2006, 1.1 billion people lack access to water and 2.6 billion are without adequate sanitation. The lives of these people are blighted by disease, poverty and indignity. Worldwide, a child dies every fifteen seconds from water-related diseases (Water Aid, 2006).

Many urban water supplies provided by public utilities are facing an acute crisis in many low-income countries. Capacity has fallen far lower than the exponentially rising demand; 450 million urban dwellers, particularly in marginal settlements, are excluded from piped water network which compromises their health and productivity (WEDC, 1999).

Water supply service in Ethiopia is found far below the required level. According to MoWR (2003) for all the water development activities achieved so far, the average access to safe water supply is $33.7 \%$ of the total population of Ethiopia. The average per-capita consumption in urban areas is close to 15 liter per capita per day. This can be taken as an example of a very low supply and coverage level.

As in other urban cites of developing countries, Addis Ababa, is also characterized by poor water supply services. Lack of adequate and safe water supply and sanitation remain two of the main transmitters of disease in the city, which are potential causes of the loss of life especially in the case of children. Moreover, water and sanitation inadequacies hinder economic and social development that constitutes a major impediment to poverty alleviation.

In general, lack of access to safe water is at the heart of the poverty trap, especially for women and children, who suffer in terms of illness, boring in collection water, and high opportunity cost of time for fetching water. However, the recent focus on poverty assessment research has consistently shown that improvements in water services are a critical element in designing and implementing effective strategies for poverty alleviation.

In relation to this, to improve water service in Ethiopia, the government has implemented integrated short term and long term plans. The Millennium Development Goals (MDGs) have been constituted as an integral part of the government's Sustainable Development and Poverty Reduction Program (SDPRP). One of the 
development target of the MDGs is to increase access to clean water from $30 \%$ in 2000 to $72.9 \%$ by 2015 (MoFED and UNDP, 2005).

This phenomena call for immediate efforts to improve the existing water service and promote the construction of new supplies so as to cope up with the increasing demand for water. To find solution to the existing water supply problems, the water utility needs to link itself with its customers and stakeholders for the communal advantage of the whole residents of the city.

Nevertheless, most previous studies made on the city water supply system focus on the development of supply-oriented approach. In line with this, to attain an improved water service in the city the demand oriented approach is imperative. This demand oriented approach asserts that water utility bodies need to understand actual household water use behaviour and the observed ability and willingness to pay for improved water service.

Different studies indicate that customers are willing to pay to avoid water shortages, and many customers value water supply reliability quite high if it is affordable. According to Carson and Mitchell (1987) a contingent valuation study was conducted in southern and northern California residential customers. The result showed that customers were willing to pay $\$ 142$ per year to avoid 30\% to 35\% shortage twice out of 5 years.

Therefore, the objective of this paper is to examine the determinants of the willingness to pay of water consumers for improved water service in the city. To estimate the willingness to pay for changes in water supply service, the contingent valuation method (CVM) was used. Closed-ended with a follow up was employed as the monetary elicitation tool. Thus, the result of the study is believed to help policy makers to design appropriate water pricing for full cost recovery systems under the proposed improvements.

The remaining part of the paper is structured as follows: section two deals with review of literature. The third section gives the data, elicitation method and empirical models. In the fourth section, description of variables, descriptive analysis, econometric results and discussion is presented. The last chapter deals with the summary and conclusion of the study. 


\section{Review of literature}

\subsection{Conceptual framework}

This section deals with ways in which how economists attach values to the resources provided by the natural environment. In relation to this, we deal with the theoretical foundations for the techniques that economists have developed for environmental valuation in connection with the resources. The economic approach to the valuation of resources is also discussed based on the contribution of the resources to human welfare. Whether the good or service is marketed or non-marketed, its unit economic value is determined by the welfare contributions that it makes to humans. Consequently, the need to demonstrate the importance of environmental policy is the ultimate objective of the valuation.

\subsubsection{Theoretical foundation}

The change in utility due to change in prices, quantities or both leads to a change in welfare of the society. Changes in welfare are measured in terms of each individual's personal assessment of changes in well-being. For traded commodities, the demand curve depicts the marginal WTP for the good or service. The household will consume all units of the commodity where the marginal WTP exceeds the market price. The consumer enjoys a consumer surplus for all points where the marginal WTP is higher than the market price. The welfare change associated with a change in the price of a marketed commodity is often measured using the change in consumer's surplus, derived from the Marshallian demand curve with a constant level of income.

For non market ecosystem service, the maximum WTP for an improvement in quantity or quality is the area between the initial and new levels of the resource under the demand curve. Value estimation then involves determining directly or indirectly the shapes of these marginal WTP curves for the ecosystem services.

According to Shiferaw et al. (2005) a given household maximizes its welfare (U) from consumption of a vector of marketed goods (c), ecosystem goods and services (q) and has a fixed budget $y$, such that :

$$
\operatorname{Max} U=U(c, q)+\mu\left(\mu-p^{\prime} c\right)
$$

The standard utility-maximizing solution to this problem will give the Marshallian demand function for the tradable commodity: 


$$
c^{*}=c(p, q, y)
$$

which is a function of a vector of market prices (p), the disposable income (y) and the ecosystem services (q) considered to be a public good. If this is substituted in to the utility function it could be derived:

$$
v(p, q, y)=U(c(p, q, y), q)
$$

The marginal effect of the change in the level of the public good $q_{i}$ on household welfare can be derived as:

$$
\frac{\partial v(p, q, y)}{\partial q}=\frac{\partial U(c(p, q, y), q)}{\partial q}
$$

This is equal to the marginal valuation of the environmental good. For a given change in $q$ from $q^{\circ}$ to $q^{1}$, the welfare effect on household $\mathbf{h}$ can be estimated as

$$
\Delta U^{h}=v^{h}\left(p, q^{1} y\right)-v^{h}\left(p, q^{0}, y\right)=\int_{q^{0}}^{q^{1}}\left[\frac{\partial v^{h}(p, q, y)}{\partial q}\right]
$$

The total welfare effect summed over all the affected households (h) can be calculated as:

$$
\sum_{h} \Delta U^{h}=\sum_{h} \int_{q^{0}}^{q^{1}}\left[\frac{\partial v^{h}(p, q, y)}{\partial q}\right]
$$

The compensating surplus (CS) and equivalent surplus (ES) measures (analogous to the compensated variation (CV) and equivalent variation (EV) for price changes) can also be directly derived from the indirect utility function. For an improvements in $q$ from $q^{\circ}$ to $q^{1}$ the compensating surplus (CS) and equivalent surplus (ES) measures can be computed as:

$$
\begin{aligned}
& v\left(p, q^{1}, y-C S\right)=v\left(p, q^{0}, y\right) \\
& v\left(p, q^{1}, y\right)=v\left(p, q^{0}, y+E S\right)
\end{aligned}
$$

The expenditure function for household $h$ is given by $e^{h}(p, q)$. The aggregate welfare change measures for a change in $q$ from $q^{\circ}$ to $q^{1}$ for compensating surplus (CS) can be 


$$
C S=\sum_{h}\left(e^{h}\left(p, q^{0}, u^{0}\right)-e^{h}\left(p, q^{1}, u^{0}\right)=\sum_{h} \int_{q^{0}}^{q^{1}}\left[\frac{\partial v^{h}\left(p, q, u^{0}\right)}{d q}\right] d q\right.
$$

The aggregate equivalent surplus (ES) measure for a change in $q$ from $q^{\circ}$ to $q^{1}$ can be given as:

$\mathrm{ES}=\sum_{h}\left(e^{h}\left(p, q^{0}, u^{1}\right)-e^{h}\left(p, q^{1}, u^{1}\right)=\sum_{h} \int_{q^{0}}^{q^{q}}\left[\frac{\partial v^{h}\left(p, q, u^{1}\right)}{d q}\right] d q\right.$

The compensating surplus (CS) is the maximum amount of money that the individual is willing to pay to secure an increased provision of the public good q. The equivalent surplus (ES) measures the minimum sum of money that must be given to individuals (willingness to accept) before the change to make them as well-off as they would have been following an increase in $q$. This forms the basis for valuation of nonmarketed ecosystem services.

The measure of welfare change can be either positive (a welfare gain) or negative (a welfare loss). For a proposed welfare gain the compensated variation measure tell us how much money income the individual would be willing to pay to ensure that the change occurs; while the equivalent variation measure tell us how much extra money income would have to be given to an individual for the person to attain the final improved utility level in the absence of provision change occurring.

\subsubsection{Valuing water}

Economics literature indicates that the total economic value of an environmental good is composed of two types: use-value and non-use value. The total economic value of water can be broadly defined as the maximum amount the user would be willing to pay for the use of water.

Water was involved in one of the most famous intellectual conundrums in the history of economic thought: the water-diamond paradox. This problem was resolved in the eighteenth century with the concept of a distinction between value in-use and value in-exchange. Although its price is low, water has an enormous value in-use to humans since it is a necessity to survive, while diamonds have a high value inexchange (Borgoyary M., 2002).

Historically, water was available in ample supply and therefore was treated as a free good, and continued to remain so even with increases in population and economic growth. As a consequence, many rivers and ground water sources have become 
polluted and water is now a scarce resource. Water has been traditionally provided to meet demand. However, it is becoming prohibitively expensive to resort to large-scale infrastructural solutions for providing water to meet ever-increasing demand. Hence, effective water resource management requires that water be treated as an economic good.

To argue for water to be treated as an economic good does not necessarily imply that a market price must be paid for it. What it means is that water is a scarce and valuable resource that should not be wasted, and that proper pricing (valuation) will ensure efficient utilization. But this misinterpretation of "water as an economic good" leads to a serious misunderstanding in many debate. Some people feared that the adoption of this principle would lead to economic pricing of water, which would damage the interests of the poor and make irrigated agriculture virtually unfeasible. As a result, a number of disclaimers were stating that water is also "social" good and that it should be affordable to the poor (Borgoyary M., 2002).

In a net shell, treating water as an economic good or ensuring proper valuation of it will provide powerful decision and management tools. At a macro level it will ensure efficient utilization of water both at the user level and at the project level., thereby enabling sustainable water resource management.

\subsubsection{Methods for valuing environmental resources}

Economics literature indicates that the total economic value of an environmental good is composed of two types: Use value and non-use value. The total economic value of water can

be broadly defined as the maximum amount the user would be willing to pay for the use of water.

In relation to this, various valuation methods are available to attach economic values to non-marketed environmental resources. According to Callan and Thomas (1996), these methods can be discussed under two categories: indirect method and direct methods.

\section{The indirect method}

Economists use indirect methods to make inferences about markets that are linked to the environmental good under investigation. Although there are many indirect 
estimation methods, in this study, the two common valuation methods are: the travel cost method (TCM) and the hedonic price method (HPM).

The travel cost method depends on information about the amount of money and time people spent getting in to a site to infer a value for that site. According to Callan and Thomas (1996) the travel cost method has a primary advantage of measuring environmental benefits based on actual behavior, but it ignores non-use value. Furthermore, this method focuses on recreational use, making it ineffective for estimating any incremental benefits that might be accrued to commercial users of a resource.

The hedonic price method is based on the theory that a good or service is valued for the attributes or characteristics it possesses. This perception of value suggests that implicit or hedonic price exist for individual product attributes, and these can be determined from the explicit price of the product. According to Carson (2000), however, this method does not capture non-use values that are very important when we deal with environment and hence underestimate the total economic value.

\section{The direct method}

The direct method estimates environmental benefits according to responses or observed behaviors directly tied to the environmental quality. The common method in this approach is CVM.

When market data are unavailable or unreliable, economists can use alternative estimation methods that rely on hypothetical market conditions. Such methods typically use surveys to inquire about individuals' WTP for some environmental policy initiative. This survey approaches to benefit estimation is known as the CVM because the results are dependent up on the hypothetical market devised. CVM is based on classical economic theory using Hicksian technique, that is, either compensation variation (willingness to pay) for improved environmental services or equivalent variation (willingness to accept) compensation for environmental deterioration.

The CVM first came into use in the early 1960s by Economist Robert K. Davis in 1963 when he used questionnaire to estimate the benefits of outdoor recreation in a Marine backwoods USA. Since then, the contingent valuation technique has been utilized by various economists to measure the benefits of a variety of goods including recreation, hunting, water quality and toxic waste dumps (Mitchell and Carson, 1989). 
Although a number of researchers have employed the CVM, using such survey method has some basic problems in the sense that survey respondents could give biased information ${ }^{4}$. However, CVM is widely applicable and applied monetary valuation method despite its limitations. It has potential application to a wider range of environmental goods than any other valuation techniques. It has strong theoretical basis with unique advantage that it estimates income compensating welfare measures. When surveys are properly planned and executed, most of the CVM problems can be eliminated and it would be one of the best methods for estimating environmental benefits. In this study, the value of improved water supply service in Addis Ababa city is estimated by using CVM to measure WTP. Domestic water consumers' were asked questions on their willingness to pay for improved water services.

In general, CVM helps researchers to capture the total value of the good: both use and non-use values and its flexibility facilitate valuation of a wide range of nonmarketed goods. As a result, this method is becoming the most preferred valuation at present. Thus, based on the reasons mentioned above CVM is employed for this study.

\subsection{Empirical review}

The contingent valuation method has found extensive application in recent years in valuing of environmental benefits, the benefit of reduced air pollution, valuing of water quality, valuing of improved solid waste management and the option or existence valve of ecologically important species.

According to Carson et al. (1996) and Hanemann $(1994,1996)$ a number of theoretical and methodological issues and criticisms have been raised concerning the application of the CVM in general and in valuation in developing countries in particular. A look in to a literature indicates that, at least at the theoretical level, a large number of criticism were linked with problems in the details of specific studies, such as how the questionnaire is prepared and data are collected and analyzed.

However, according to Whittington (1998) it is now assumed by many environmental and resource economists and policy analysts working in developing countries that contingent valuation surveys are straight forward and easy to do.

\footnotetext{
${ }^{4}$ For a detailed discussion of the critiques on CVM, see Callan and Thomas (1996).
} 


\subsubsection{CVM applications in water supply studies: the Ethiopian experience}

The Ethiopian experience reveals that limited CVM studies have been conducted to investigate factors that influence households' willingness to pay for improved water supply in rural and urban areas. Some of the studies are given as follows.

Fisseha (1997) used a contingent valuation method to assess consumer's willingness to pay for an improved water supply service, on Meki town, Ethiopia. The study selected a sample of 246 households which were chosen randomly. The study used multinomial ordered probit model. The result showed only income and the time cost of fetching water to be significant determinants of WTP for improved water in the town.

Dunfa (1998) also employed contingent valuation method on estimating willingness to pay for rural water supply Ada'a-Liben district with a sample of 228 households, central Ethiopia. The study employed an iterative bidding game. The study employed order probit model. The study result showed the peasant households' willingness to pay for improved rural water provision was positively influenced by income of the household, distance (time it takes to fetch water), quality of current water source and credit.

In Harar town eastern Ethiopia, Genanew (1999) analyzed determinants of households' willingness to pay and demand for improved water services. The study used iterative bidding game. Multivariate regression based on the ordinary least squares and the ordered probit models were used to analyze the determinants of WTP for improved piped water service. Variables such as: household income, education level, sex, location of study site, starting point of the bidding game, main sources of water and serious problem of the existing water service were found statistically significant on willingness to pay for both models.

Using a contingent valuation method, Alebel (2004) also examined the affordability and willingness to pay for improved water supply in urban areas of Ethiopia taking Nazareth town as a case study. The value elicitation method used in the study was bidding game and a total of 307 sample households were covered during the survey. The study used a censored least absolute deviation (CLAD) which does not need the normality and homoscedasticity assumption of the distribution of the error term to get consistent estimate. The results of the CLAD regression showed that income, monthly expenditure for water consumption, quality and time taken to fetch water from the existing source significantly affects the respondent's willingness to pay. 


\subsubsection{CVM applications in water supply studies: the developing countries' experience}

Whittington et al. (1990) estimated individuals' WTP for improved water services in rural areas of southern Haiti using the ordered probit model. The study concluded that WTP of individual respondents were affected by household wealth, education level of respondents, distance of the household from the existing water sources, quality of water and sex of respondent. The results of the study also suggested that it is possible to do a contingent valuation among a very poor, illiterate population and obtain reasonable answers.

In rural areas of Punjab in Pakistan Altaf et al. (1992) conducted a contingent valuation study with the main objective of identifying determinants of households' WTP for improved rural water supply and comparing the contingent valuation study results with market-based results. The authors found that wealth and education of respondents were among the major factors that affect respondents' WTP for improved rural water services. Empirical results of the study also confirmed that the contingent valuation study results seem consistent with revealed preference results.

Montes et al. (2003) conducted a study on assessing the willingness to pay for maintained and improved water supplies in Mexico city. The result showed the poorer households were primarily concerned with securing reliable services, while wealthier households which already enjoy better services were willing to pay higher amounts to avoided services deterioration than for improvements. The study demonstrates how WTP results can be used to create equity based policy of water tariff reflecting income distribution. The aggregated WTP amounts show that the authorities could collect sufficient resource for both service modernization and could also reduce existing subsidies by about $70 \%$.

Abdalla (2003) also used CVM to estimate the value of improvements in water supply reliability in Zanzibar town. Random samples of 300 households were drawn from the survey. The study implements probit model and OLS regression model to statistically estimate the influence of different households socio-economic and other variables on the household decision on WTP for water services. The probit analysis indicated that three variables were significantly correlated with the household decision to pay for improved services. These are education, past payment and experience on availability problem. Similarly, OLS analysis indicated that only one factor (experience on water availability problem) was significant. 


\section{The data, elicitation method and empirical models}

\subsection{The data}

In order to fulfill the above mentioned objective, the study was designed to gather information and necessary data from various sources. The study uses a combination of primary and secondary data. The data used in this study are mainly primary and cross sectional for the year 2006/07 from Addis Ababa. The secondary data was collected from Addis Ababa Water and Sewerage Authority (AAWSA), Ministry of Water resources (MoWR), Central Statistical Authority (CSA), Bureau of Finance and Economic Development (BoFED), and other various published sources including journals, development reports, research articles and websites.

The main data source is a contingent valuation survey conducted in Addis Ababa city. The study employed CVM to solicit the respondents' WTP for improved water services. The contingent valuation survey questionnaire used in this study was designed to include hypothetical description of the good being valued, socioeconomic and demographic characteristics of household, existing water supply situation, water usage and general perception questions. The sample for the study was drawn from three out of ten administrative sub-cities in Addis Ababa, covering a total of six kebeles ${ }^{5}$. A stratified proportional random sample of 240 households was used in the survey, out of which 235 of them were found usable. In-person interview was used in the administration of the survey which was feasible option to the inhabitants of the city ${ }^{6}$.

A stratified two-stage sample design was adopted. At the first stage 3 sub-cities based on CSA (2004a) study of the economic establishment standards were selected which called Primary Sampling Units (PSUs). Accordingly, Addis-Ketema, Nefas-Silk Lafto, and Bole were selected from lower, medium and higher economic standards, respectively. The household in each sub-city was selected proportionally. From the total 126,108 households, Addis Ketema, Nefas-Silk Lafto and Bole were selected 44,921 (35.6\%), 42,978 (34.1\%), and 38,209 (30.3\%) households, respectively.

\footnotetext{
${ }^{5}$ Kebele is the smallest administrative unit in the city. The city is divided in to sub-cities which in turn divided in to kebeles. According to BoFED (2004) there are 10 sub-cities and 203 kebeles in Addis Ababa city.

${ }^{6} \mathrm{~A}$ total of five enumerators and two supervisors including the researcher participated in the actual survey. All the enumerators were selected based on their previous experience in household survey. Both enumerators and supervisors were given two day training. Cooperation to be interviewed was managed through kebele officials.
} 
Accordingly, from the sample of 240 households 85,84 and 71 were from AddisKetema, Nefas-Silk Lafto and Bole, respectively.

At the second stage, 2 kebeles were selected from each sub-city based on the water supply availability (Table1 column 6), which is the Second Stage Unit (SSU). AAWSA map indicates that each kebele of the city is segregated to the respective water supply availability (Zerihun, 2005). Hence, from Addis-Ketema sub city both, kebele 14 and 19 were selected based on water supply availability which is 7-16 and 17-24 hrs/day, respectively. Moreover, out of the total 16,268 households of the six kebele, 1,287 and 1,670 households were drawn from kebele 14 and 19, respectively. Finally, from a sample of 85 households in Addis-Ketema, 37 and 48 households were drawn from kebele 14 and 19 on the base of stratified proportionate random sampling, respectively. The sampling procedure for both Nefas-Silk Lafto and Bole sub-cities were similar steps to that of Addis-Ketema sub-city (Table1).

Table 1: Summary of sample households (HHs) from each sub-city and kebele

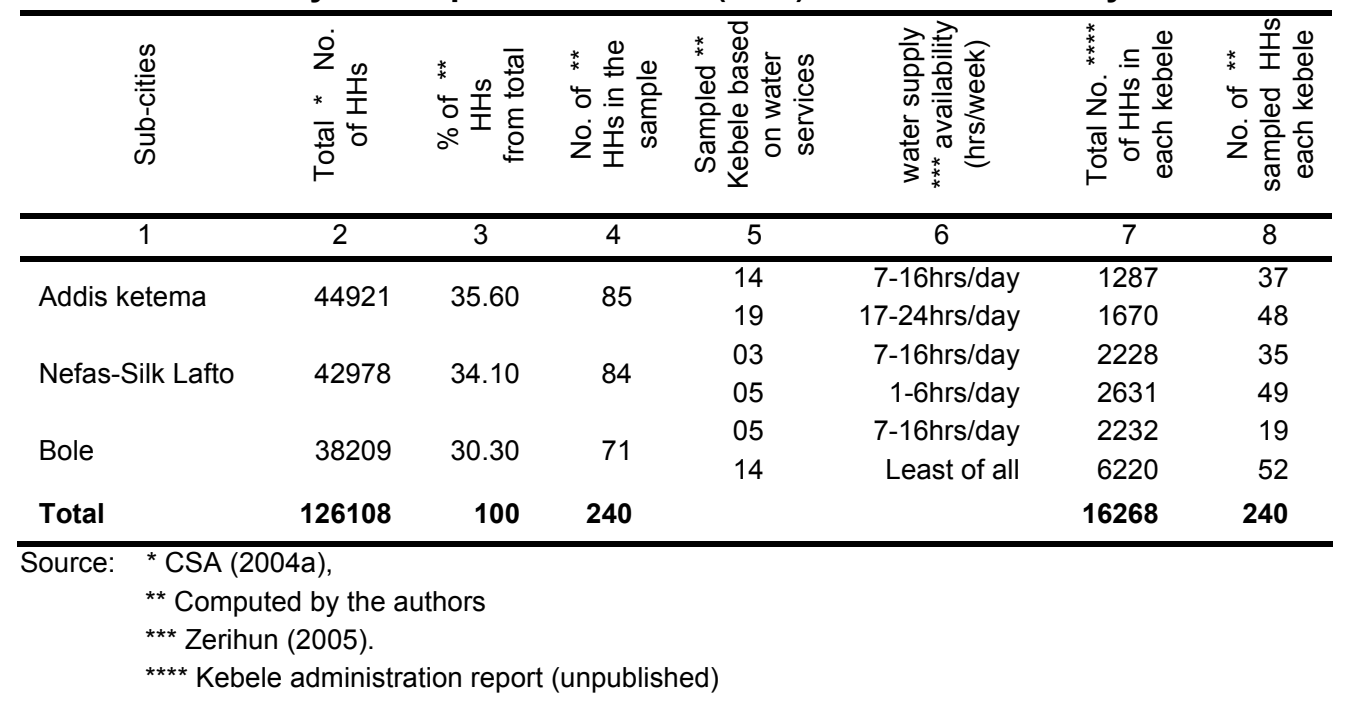

To select the respondent from every kebele, the kebele itself was chosen as a reference point during the survey. After the stratified two-stage sample design, the first household was selected around the kebele based on random method. After the selection of the first household, the remaining households were selected on equal paced interval (every $15^{\text {th }}$ ) based on spatial distribution till the households in each kebele were drawn completely. 


\subsection{Elicitation method}

In this study, among various elicitation formats, the single-bounded dichotomous choice format with a follow up question was chosen to obtain a household's willingness to pay for a proposed scenario ${ }^{7}$. Green et al. (1995) indicated that the main reason for using this format is to provide far more information on WTP and information on plausibility of responses than other alternatives. The WTP scenarios' questionnaire that was used for this paper is presented in Appendix (1).

In this study we used three different scenarios. The first is households who have private tap connection and willing to have improved water service. The second is households who do not have private tap connection but willing to connect for improved water service. The third is households with no private tap connection but willing to have improved public tap service. Note that households that are going to connect either private tap or public tap may not be required to pay initially the costs of connection to the new scheme. Instead, the authority will cover the costs of provision with insignificant increase in the monthly tariff rate. And every household will have improved water supply service. By an improved provision of water, we mean good quality of water which is safe for health and good quantity of water which is available for 24 hours per day.

Before implementing the final survey we conducted the pilot survey using open-ended elicitation format to set up starting bids ${ }^{8}$ In the actual survey the total sample households were randomly divided in to three groups of equal size and each

\footnotetext{
${ }^{7}$ In using a single-bounded dichotomous choice format with a follow up question the respondents are asked simple "Yes" or "No" questions of the stylized form to the initial bid and are asked to state their maximum willingness to pay. Other methods include open ended, bidding game, and payment card. For details on these, see Mitchell and Carson (1989).

${ }^{8}$ Pre-testing was made in each of the 6 kebeles. We selected a random sample of three households from each kebele and a total of 18 household heads were interviewed under the pilot survey. This was done by three experienced interviewers and the researcher himself. The purpose of the pre-testing was to make some possible modification in the design of the questionnaire based on the responses so as to make it understandable for respondents. Furthermore, the pilot survey helps to set the starting price in the elicitation part of the questionnaire. During the pilot survey, the willingness to pay part was open ended. During the pilot survey on willingness to pay, different answers were observed ranging from 2.5 cents to 20 cents per bucket. However, the pilot survey revealed that 5,10 and 15 cents per bucket were the most frequent prices. Out of 18 sample households that were used during pilot survey, the frequency of 5,10 and 15 cents per bucket were 6,5 and 4 , respectively. The frequency for 2.5 and 20 cents per bucket were found to be 1 and 2 , respectively. Thus, we used the most frequent prices as starting points of the WTP for a single bounded dichotomous choice.
} 
contained 80 households and the three different starting bids (5, 10 and 15 cents per bucket of water) were assigned to households in the different groups.

\subsection{Empirical models}

\subsubsection{The Tobit Model}

The tobit model is a censored regression model. Observations on the Latent variable $\mathbf{Y}$ are missing (or censored) if $\mathbf{Y}^{*}$ is below a certain threshold level. One of the applications of the tobit model is when the dependent variable (for our case maximum WTP) is zero for some individuals in the sample (Maddala, 2002).

The tobit model is used to identify factors that affect the willingness to pay of households for the proposed improvements in water supply services. In addition to this, in the tobit model our interest is in finding out the amount of money a respondent spends on improved water services in relation to socio-economic and demographic variables. According to Greene (1997), the general formula of the tobit model is given as follows:

$$
Y^{*}=\beta^{\prime} X_{i}+u_{i}
$$

Suppose $\mathrm{Y}^{*}$ is observed if $\mathrm{Yi}^{*}>0$ and is not observed if $\mathrm{Yi}^{*} \leq 0$. Then the observed $\mathrm{Yi}^{*}$ will be defined as

$Y i=Y i^{*}=\beta^{\prime} X_{i}+u_{i}$ if $Y^{*}>0$

$$
=0 \text { if } \mathrm{Yi}^{*} \leq 0 \text {. }
$$

\section{Where}

$\boldsymbol{\beta}^{\prime}=\mathrm{A}$ vector of coefficients

$\mathbf{X}_{\mathbf{i}}=\mathrm{A}$ vector of explanatory variables

$\mathbf{u}_{\mathbf{i}}=$ The error terms that are independently and normally distributed with mean zero and a common variance $\delta^{2}$.

Estimation of the tobit model is similar to that of truncated regression. Following Greene (1997) the log likelihood for the censored regression model is

$$
L n L=\sum_{y i>0}-\frac{1}{2}\left(\ln (2 \pi)+\ln \delta^{2}+\frac{\left(y i-B^{1} x i\right)^{2}}{\delta^{2}}\right)+\sum_{y i=0} \ln \left[1-\phi \frac{\left(B^{1} x_{i}\right)}{\delta}\right]
$$


The two parts correspond to the classical regression for the non limit (continuous) observations and the relevant probabilities for the limit (zero) observations, respectively.

Based on the above behavior of the model, tobit analysis is appropriate for this study. The equation in this tobit model is indicated as follows.

$$
\begin{aligned}
& \text { MWTP }_{i}{ }^{*}=\mathrm{B}_{0}+\mathrm{B}_{1} I \mathrm{NCH}+\mathrm{B}_{2} \mathrm{FAMS}+\mathrm{B}_{3} \mathrm{WEAH}+\mathrm{B}_{4} \mathrm{SEXR}+\mathrm{B}_{5} \mathrm{AGER}+\mathrm{B}_{6} \mathrm{EMPR}+ \\
& \mathrm{B}_{7} \mathrm{ATTR}+\mathrm{B}_{8} \mathrm{LOC}_{\mathrm{AK}}+\mathrm{B}_{9} \mathrm{TANK}+\mathrm{B}_{10} \mathrm{STAT}+\mathrm{B} 11 \mathrm{INFO}+\mathrm{B}_{12} \mathrm{IB}+ \\
& \mathrm{B}_{13} \mathrm{STAY}+\mathrm{B}_{14} \mathrm{SATI}+\mathrm{B}_{15} \mathrm{EDUC}_{1}+\mathrm{B}_{16} \mathrm{EDUC}_{2}+\mathrm{B}_{17} \mathrm{EDUC}_{3} \\
& +\mathrm{B}_{18} \mathrm{LOC}_{\mathrm{BO}}+\mathrm{U}_{\mathrm{i}}
\end{aligned}
$$

MWTP $_{\mathbf{i}}{ }^{*}=$ maximum willingness to pay for improved water services. And MWTP* is a latent variable which is not observed when it is less than or equal to zero but is observed if it is greater than zero.

$B_{0}, B_{1},----=$ are coefficients, $i=1,2,3$,

The description of all variables of the above regression are given in Appendix (2)

\subsubsection{The Probit Model}

In the probit model of single bounded dichotomous format, households are given initial bid which they may accept or reject. The basic model for analyzing dichotomous contingent valuation responses is the random utility model. A study by Hanemann (1984) indicates that he had constructed the basic model. The central theme of this theory is that although an individual knows his/her utility certainly, it has some components which are unobservable from the view point of the researcher. As a result, the researcher can only make probability statement about respondent's "yes" or "no" responses to the proposed scenario.

The indirect utility function for the $\mathrm{j}^{\text {th }}$ respondent can be specified as follows:

$$
\mathbf{U}_{\mathrm{ij}}=\mathbf{U}_{\mathrm{i}}\left(\mathbf{Y}_{\mathrm{j}}, \mathbf{X}_{\mathrm{j}}, \varepsilon_{\mathrm{ij}}\right)
$$

Where $Y_{j}=j^{\text {th }}$ respondent's income

$i=1$ denotes the final state and $i=0$ the status quo (the initial state)

$\mathrm{X}_{\mathrm{j}}=$ vector of household characteristics and attributes of a given choice

$\varepsilon_{\mathrm{ij}}=$ random component of the given indirect utility 
If a payment (the initial bid, $\beta_{\mathrm{i}}^{*}$ ) is introduced due to improvement in water supply service, the household accepts the proposed bid only if the utility with the contingent valuation program, net of the required payment, exceeds utility of the status quo.

$$
\mathbf{U}_{1}\left(\mathbf{Y}_{\mathrm{j}}-\beta_{\mathrm{i}}{ }^{*}, \mathbf{X}_{\mathrm{j}}, \varepsilon_{1 \mathrm{j}}\right)>\mathbf{U}_{0}\left(\mathbf{Y}_{\mathrm{j}}, \mathbf{X}_{\mathrm{j}}, \varepsilon_{0 \mathrm{j}}\right)
$$

For the researcher, however, the random components of preferences cannot be known and s/he can only make probability statement of "yes" or "no" responses. Thus, the probability that the respondent says "yes" or "no" is the probability that s/he thinks that $s /$ he is better off in the proposed program. For individual $j$, the probability is:

$$
\operatorname{Pr}\left(\operatorname{Yes}_{\mathrm{j}}\right)=\operatorname{Pr}\left(\mathbf{U}_{1}\left(\mathbf{Y}_{\mathrm{j}-}-\beta_{\mathrm{i}}^{*}, \mathbf{X}_{\mathrm{j}}, \varepsilon_{1 \mathrm{j}}\right)>\mathbf{U}_{0}\left(\mathrm{Y}_{\mathrm{j}}, \mathbf{X}_{\mathrm{j}}, \varepsilon_{0 \mathrm{j}}\right)\right.
$$

This probability statement provides an intuitive basis to analyse binary responses. Assuming the utility function is additively separable in deterministic and stochastic preferences:

$$
\mathbf{U}_{i}\left(\mathbf{Y}_{j}, \mathbf{X}_{j}, \varepsilon_{i j}\right)=U_{i}\left(Y_{j}, X_{j}\right)+\varepsilon_{i j}
$$

with the additive specification of Equation 18, the probability statement for respondent j becomes:

$$
\operatorname{Pr}\left(\operatorname{Yes}_{\mathrm{j}}\right)=\operatorname{Pr}\left[\mathrm{U}_{1}\left(\mathrm{Y}_{\mathrm{j}}-\beta_{\mathrm{i}}{ }^{*}, \mathbf{X}_{\mathrm{j}}\right)+\varepsilon_{1 \mathrm{j}}>\mathrm{U}_{0}\left(\mathrm{Y}_{\mathrm{j}}, \mathrm{X}_{\mathrm{j}}\right)+\varepsilon_{0 \mathrm{j}}\right]
$$

The goal of estimating econometric (or parametric) models from dichotomous choice of contingent valuation responses is to calculate mean WTP for the services described. In addition, parametric models allow for the incorporation of respondent characteristics in to the willingness to pay functions (Haab and McConnell, 2002). In this study we discuss the effect of socio-economic and demographic factors of the respondent on WTP with the help of tobit model. In connection to this, the probit model in this study is used to calculate mean willingness to pay for the closed -ended format.

The Probit model can be defined as:

$\mathrm{Ti}^{*}=\beta^{\prime} \mathrm{X}_{\mathrm{i}}+\mathrm{u}_{\mathrm{i}}$

Where

$\beta^{\prime}=$ Vector of the parameter of the model coefficients

$X_{i}=$ Vector of explanatory variables

$\mathrm{u}_{\mathrm{i}}=$ The error term assumed to have normal distribution with zero mean and

a common variance $\delta^{2}$ (Greene,1997) 
$\mathrm{Ti}^{*}=$ Unobservable households' actual WTP for improved water supply services. Ti*is simply a latent variable. What we observe is a dummy variable $W T P_{i}$, which is defined as: WTPP $_{i}=1$ if Ti* $\geq \beta_{i}^{*} \quad \mathrm{WTP}_{\mathrm{i}}=0$ if $\mathrm{Ti}^{*}<\beta_{\mathrm{i}}{ }^{*}$.

In the single bounded elicitation format, the $i^{\text {th }}$ respondent is asked if $\mathrm{s} /$ he would be willing to pay the initial "bid", $\left(\boldsymbol{\beta}_{\mathrm{i}}{ }^{*}\right)$ to get improved water supply services.

\section{Description of variables, descriptive analysis, econometric results and discussion}

\subsection{Description of explanatory variables}

The hypothesis that is being tested in this analysis indicates how households' socio economic and demographic factors affect the household's decisions on WTP for improved water services. This study collected several households' demographic and socioeconomic factors as well as current status of water services. Therefore, those variables are considered to determine the willingness to pay and willingness to connect to the new improved water supply services are given in Appendix(2).

\subsection{Summary of descriptive analysis of the CVM survey}

A total of 240 sample households were interviewed in the survey. Out of this total sample, only 235 were analyzed and the remaining 5 were removed due to protest zero $^{9}$. Thus, from the total of 235 sample respondents, $140(59.6 \%)$ are head of the households and the rest $95(40.4 \%)$ are not. Out of total respondents, $167(71 \%)$ are female and the rest $68(29 \%)$ are male. The average family size of the total sample household is 4.79 and ranges from 1 to 10 . Their level of education ranges from none to higher education graduates. Out of the total respondents, $52(22.1 \%)$ were categorized under illiterate group. Those with formal education of grade 1 to 6 grades (primary education) constitute $57(24.3 \%)$ of the total respondents. Those with formal education from grade 7 to 12 grades are $81(34.4 \%)$ and grouped under secondary school. Only $45(19.1 \%)$ of the respondents have attained formal education above grade 12 of higher education (tertiary school).

\footnotetext{
${ }^{9}$ From the total 240 observations of the sample, 14 (5.83\%) of the households were not willing to pay any amount. To know the reason why they are not willing to pay any amount, and to decide whether their response is protest or true zero, a follow up question was asked. From the result of the study, it indicated that only $5(2.08 \%)$ of the respondents can be classified as a protest zero. These are the once who believe that the existed water service was satisfactory or the government should pay. Thus, we say both these responses are protest zero and they are eliminated from analysis. However, 9 (3.75\%) of the respondents were not willing to pay any amount for the reasons such as inability to pay (too poor to pay). These are a true zero and all are included in our analysis.
} 
The average monthly income of the sampled household was Birr 1339.33 ranging from the minimum of Birr 110 to the maximum of Birr 8,500 per month ${ }^{10}$. The mean household consumption of water was 9 bucket (180 litters) per day. Based on this information, the average household's water consumption per month was 5,400 liters (which is $5.4 \mathrm{~m}^{3} /$ month). For the year $2006 / 07$, the minimum water consumption block tariff rate of AAWSA for less than $7 \mathrm{~m}^{3}$ is birr $1.75 / \mathrm{m}^{3}$. Thus, on average, the household's water consumption expenditure is Birr 9.45 per month.

As compared to the mean monthly income of the households (that is, Birr 1339.33), households in the sampled area spend only $0.71 \%$ (excluding meter fees) of their income on water. Though, this is with in the range of the World Bank's recommendation, which states a household should not spend more than $5 \%$ of his monthly income on water, it is far below the recommended level. This suggests that the households in the sampled area can spend for improved and reliable water supply services.

The other finding of the study showed the mean per capita consumption of the sample household was around 37.6 liters per day. However, according to Gleick (2001) the absolute minimum per capita per day of water is 50 liters based on the United Nation's target. The amount in the study area is below this minimum requirement.

Data for the wealth of the households, which was proxy by whether the household owns house or not, showed that $99(42.2 \%)$ live in rented houses from individuals, kebeles and government while $136(57.8 \%)$ of the interviewed households live in their own houses. Among those who live in their own houses 65 (47.79\%), 45 (33.08\%) and 26 (19.135) were from higher, medium and lower economic standard groups, respectively.

The study also tried to look whether the household uses tank as storage of water or not. The survey finding indicated that out of total households in the survey area, 71 $(30.21 \%)$ of the respondents said they own tanks for water storage to cope with low water pressure and water outage. Out of those households who have tanks as a storage of water $42(59.15 \%)$ of the respondents said the storage allow them continuous water supply while the remaining $29(40.85 \%)$ of the respondent said the storage does not allow them continuous water supply.

\footnotetext{
${ }^{10}$ The exchange rate at the time of survey was 1 USD $=$ Birr 8.38
} 
Out of those households who know tariff rate increment, 73(39.89\%) said AWSAA'S tariff rate increment is high, $99(54.09 \%)$ said AAWSA'S tariff rate increment is medium, the remaining $11(6.01 \%)$ of the households said the tariff rate increment is low. With regard to households' water consumption due to increase in tariff rate, $148(80.88 \%)$ of the household responded that no change in their consumption, $35(19.12 \%)$ said their consumption decrease. This implies that the households' water consumption would not be affected by tariff rate increment. Hence, if AAWSA revised a new tariff rate for cost recovery system, the households' water consumption may not be affected and, hence, might be affordable by the majority of the residents.

The mean willingness to pay for the whole sample is 15.34 cents (ranging from 0 to 50 cents) per bucket of water, which implies that the sample sub-cities were willing to pay more than the current tariff rate which is 3.50 cents per bucket of water for the lowest consumption block and 7.60 cents per bucket for the highest consumption block.

Of the three strata, it was found that the highest mean WTP of 18.96 cents per bucket in area with higher economic standard. The mean WTP from the medium economic standard and lower economic standard groups were 12.33 and 15.34 cents per bucket, respectively. The result showed that households from the low economic standard group were willing to pay more than households in the medium economic standard group. The reason is out of the total public taps in the sample, $81.85 \%$ of the public tap users were in the low economic standard group. Thus, these households are more willing to pay for improved water service to avoid long queue.

The other finding of the survey indicated that, out of the total observations 91 $(38.72 \%)$ of the households have no private pipe lines, out of which $11(12.09 \%), 27$ $(29.67 \%)$ and $53(58.24 \%)$ are from higher, medium and lower economic standard groups, respectively. Out of 91 respondents with no private tap connection, 44 $(48.3 \%), 30(32.9 \%)$ and $17(18.6 \%)$ of the households get water from public tap, shared tap and private vendors, respectively. Where as the remaining $144(61.28 \%)$ of the households have private pipe lines, out of which $61(42.36 \%), 56(38.89 \%)$ and $27(18.75 \%)$ were from higher, medium and lower economic standard groups, respectively.

The other observation from the study result indicated that households' with no access to private pipe line were more willing to pay than households' with access to private pipe lines. The reason is probably households who don't have private pipe line spend a lot of time to fetch water from outside source. Moreover, these households may buy water from vendors at relatively higher price than the authority's tariff rate. Hence, 
households with no access to private pipe lines show more preference to the improved service than the counter part. The summary of descriptive statistics for the variables used in the multivariate regression analysis is given in Appendix (3).

\subsection{Econometric results and discussions}

In this section, results obtained from regression estimation of willingness to pay equation are presented. As mentioned above, two maximum likelihood estimates has been undertaken.

According to the rule of thumb if the variance inflation factor (VIF) of a variable exceeds 10 , that variable is said to be highly collinear. However, a test was made to check whether or not the problem existed is severe or nor. The result indicated multicollinearity is not a serious problem as the VIF lies in a range $1.10-2.40$ with mean VIF of 1.63.

A test for the presence of heteroscedasticity problem in the model was also done. The test result shows that the null hypothesis of homoscedasticity is rejected implying that there is heteroscedasticity problem in the model, which is expected from survey of the cross sectional data (see Appendix 4). Because of this problem the study can not use a simple tobit model but a hetroscedastic tobit model (results corrected for hetroscedasticity) using LIMDEP Version 7.0.

A test for measures of model goodness of fit was also done with model chi-squared statistic $\left(L R_{\text {Model }}\right)$. The likelihood ratio (LR) chi-squared measures the overall significance of the model with the null hypothesis that all parameters associated with covariates are zero is rejected at $1 \%$ significance level. Thus, the model is statistically acceptable. It implies that the model is acceptable to explain the relation between willingness to pay and its explanatory variables ${ }^{11}$.

To check for the existence of starting price bias, the starting bid is used in the model as an explanatory variable. To check whether or not asking representatives of the households rather than the heads affects the willingness to pay responses, a dummy variable (status of the respondent) taking 1 if the head is the respondent; 0 otherwise is included in the model. To capture the effect of stratification, the location of the study area $L O C_{B o}$ is dummy variable taking 1 if it is Bole sub-city, 0 otherwise. $L O C_{A K}$

\footnotetext{
${ }^{11}$ For a detailed discussion of goodness of fit, see Habb, T.C., an McConnell, K.E. (2002).
} 
is dummy variable taking 1 if it is Addis-Ketema sub-city, 0 otherwise are included in the model.

\subsubsection{Tobit Model: Results and discussion}

The Tobit results obtained using a Limdep Version 7.0 are given in Table 2

\section{Income of the household}

The variable consistent with a priori expectations is monthly income of the household. It is significant at $1 \%$ and has the expected positive sign. This result confirms with economic theory, which states that an individual's demand for a particular commodity depends on his/her income, and that income and quantity demanded are positively related, except in the case of inferior goods. The result of the survey shows higher income group are more willing to pay for an improved water supply service than lower income group. Hence, the income of the households needs to be considered to introduce a new tariff rate structure which will help to cover the financial costs of the proposed improvements.

\section{Education level of the respondent}

From the four categories of educational level, the illiterate group is taken as a bench mark group to avoid a dummy variable trap. The other three educational dummies show positive effect on willingness to pay amount as compared to the bench mark group. The primary education dummy is not significant at $10 \%$ level of significance. The secondary and tertiary education dummies are significant at $10 \%$ level of significance. This may be due to the fact that as compared to the bench mark group the households of secondary and tertiary education groups are more aware about health and sanitation benefits of the improved water services.

\section{Employment status of the respondent}

The variable employment status of the respondent is found to be positive and significant at $10 \%$, as expected. The result is consistent with the idea that those respondents who are employed in government organization, private organization, NGO's, own business and other related areas are more willing to pay than unemployed respondents. This is because the exposure of household that is working in different sectors is expected to understand the benefits of improved water services and their effect on human being than the other group. 


\section{Wealth of respondent}

In this study ownership of house is used as a proxy to wealth. As expected, this variable is found positive and highly significant at $1 \%$ level of significance. That is, those households living in their own houses are more willing to pay for the proposed improvements than those living in rented houses. This may be the fact that households who own private houses are concerned more to pass the improved water services to their children (bequest value) than those households who do not own private houses.

Table 2: Tobit estimates for the determinants of WTP for improved water supply services (Heteroscedastic Tobit) ${ }^{12}$

\begin{tabular}{lccccc}
\hline Variable & Coefficient & Std. Er & b/St.Er. & P-Values & Mean of X \\
\hline CONST & 4.449472436 & 2.2901043 & $1.943^{*}$ & .0520 & \\
INCH & .0001715432 & .0000533710 & $3.214^{* * *}$ & .0013 & 1339.3285 \\
SEXR & .2582252614 & .14324646 & $1.803^{*}$ & .0714 & .71063830 \\
AGER & -.0022208961 & .0059684669 & -.372 & .7098 & 34.974468 \\
FAMS & -.0845664581 & .036997020 & $-2.286^{* *}$ & .0223 & 4.7872340 \\
EDUC1 & .2114814859 & .18721616 & 1.130 & .2586 & .24255319 \\
EDUC2 & .3564540480 & .21652342 & $1.646^{*}$ & .0997 & .34468085 \\
EDUC3 & .4393207847 & .22956193 & $1.914^{*}$ & .0557 & .19148936 \\
STAY & .01643804708 & .0056196780 & $2.925^{* * *}$ & .0034 & 19.952837 \\
TANK & .5254671750 & .16506017 & $3.183^{* * *}$ & .0015 & .69787234 \\
ATTR & -.1906904134 & .14743595 & -1.293 & .1959 & .78297872 \\
WEAH & .5896728854 & .16945571 & $3.480^{* * *}$ & .0005 & .57872340 \\
EMPR & .2621695535 & .15043565 & $1.743^{*}$ & .0814 & .37446809 \\
INFO & .1029382746 & .16798658 & .613 & .5400 & .77446809 \\
SATI & .3998056983 & .17182031 & $2.327^{* *}$ & .0200 & .83829787 \\
IB & .02389464906 & .015496762 & 1.542 & .1231 & 9.9787234 \\
STAT & .1276074785 & .16764284 & .761 & .4465 & .59574468 \\
LOC & .6530232215 & .18891336 & $3.457^{* * *}$ & .0005 & .34042553 \\
LOC & .1933452929 & .17510182 & 1.104 & .2695 & .30638298 \\
& Log likelihood=-773.2196 Restricted log likelihood $=-836.6690$ & \\
\hline SOU & Nof Observations $=235$ & & & &
\end{tabular}

Source: Own survey result, 2006

${ }^{* * *},{ }^{* *},{ }^{*}$ indicate significance at $1 \%, 5 \%$, and $10 \%$ levels respectively.

\footnotetext{
${ }^{12}$ Some literatures indicate that direct interpretation for the marginal effect of tobit model is not easy, since the change in $\mathrm{Xi}$ has two effects. It affects the conditional mean of the dependent variable $\mathrm{Yi}^{*}$ (in our case maximum WTP) in the positive part of the distribution and it affects the probability that the observation will fall in that part of the distribution, see Greene (1997).
} 


\section{Sex of respondent}

This variable has a positive sign as expected and is significant at $10 \%$ level of significance. This shows that female respondents are more willing to pay to connect improved water services than male. This result really tells us the experience of most developing countries with regard to gender. It indicates that female headed households are primarily responsible for the task of fetching water and hence greater preferences for improved water services by paying more as compared to their counter male headed households.

\section{Family size of the household}

Family size of the household variable was found to be significant at $5 \%$ with a negative parameter estimates. This suggests willingness to pay for improved water services decreases as family size of the household increases. The reason could be large family size of households' increase their water consumption which could discourage the family due to high bill charge services and hence willing to pay less for the proposed improvements than small size households.

\section{Household use of tank for water storage}

Households who do not use tank as storage for water was another variable found to be significant at $1 \%$ level of significance. Since the parameter estimate is positive, it implies that households who don't use tank as storage for water tend to be willing to pay more as compared to households who own tank. This indicate that households who do not use tank as a storage for water frequently suffer from low water pressure and water tap interruptions than households who use tank as a storage. These households are forced to buy water from vendors at higher price than the AAWSA tariff rate.

\section{Household year of stay in the house}

The variable household's year of stay in the house is positive and it is significant at $1 \%$ level of significance. That is, those households who have been stayed in a particular house for long year are more willing to pay for the proposed improvements than their counter parts. The possible reason could be those households that are staying for a long year in that house are mostly in the older quarter of the city. The majority of the houses in this old quarter of the city are poor in terms of infrastructure and social facilities. 
A related problem especially in the old quarter of the city is that un-planned houses and overlapping lots contribute to a high rate of unaccounted for water (UFW) due to leakage and illegal connection. The replacement and maintenance services due to old age of pipe for the household in the old settlement is poor since AAWSA at this time focuses on expanding service for un-served households. The above mentioned reasons exacerbate the existing water supply problem in the old quarter of the city and thus the households that are staying long in that area are more willing to pay for improved water services as compared to short stayed households.

\section{Location of the study sites}

Addis Ketema site dummy was positive and significant at $1 \%$ level of significance, suggesting that household in this site is willing to pay more than the bench mark (Nefas-Silk Lafto) site, keeping all other things constant. The possible reason could be that considerable part of the households in the former sub-city use public tap and hence they incur high costs in terms of time and labour for fetching water from the existing water sources. Thus, households from Addis Ketema site are more willing to pay for the new improved water systems to avoid the high opportunity costs than the bench mark site.

\section{Level of satisfaction the household with the existing water services}

The coefficient for the level of satisfaction the household with the existing water services has the expected sign and statistically significant at $5 \%$ level of significance. One possible reason could be those households who are dissatisfied with the current water service due to poor quality, less quantity, unreliability and absence of own private pipe are likely to pay for improved water services than those households who are satisfied with the existing services.

\subsubsection{The Probit Model: Calculating Mean WTP}

In this study we have already discussed the effect of socio-economic and demographic factors of the respondent on WTP using the tobit model. Thus, the probit model in this study is used to calculate mean willingness to pay for the closedended format. According to Hanemann et al. (1991) one of the main objectives of estimating an empirical WTP model based on the contingent valuation survey responses is to derive a central value (mean) of the WTP distribution. According to Carlsson et al. (2002) the main reason for estimating the probit model is to obtain an estimate of mean WTP. The result is obtained through regression of the willingness 
to pay variable on intercept and initial bid variable. The regression result shows the following values.

Table 3: The probit model to calculate mean WTP

\begin{tabular}{cccccc}
\hline Variable & Coefficient & Std. Er & b/St.Er. & P-Values & Mean of X \\
\hline CONST & 2.330989231 & .34074517 & 6.841 & .0000 & \\
IB & -.1154249357 & .027824861 & -4.148 & .0000 & 9.9787234 \\
\multicolumn{2}{l}{ Dependent variables $=$ yes/no $(\mathrm{Y} / \mathrm{N})$} & Mean $=.8553191489$ & S.D. $=$ & .3525296318 \\
\hline
\end{tabular}

Source: Own survey result, 2006

Mean WTP $(\mu)$ using the model for the closed -ended format is defined as follows:

$$
\mu=-\frac{\alpha_{0}}{\alpha_{1}}
$$

Where:

$$
\begin{aligned}
\alpha_{0}= & \text { the constant term } \\
& \alpha_{1}=\text { the bid coefficient } \\
& \mu=-2.330989231 \\
& -.1154249357 \\
& =20.20
\end{aligned}
$$

Thus the mean WTP $(\mu)$ calculated from the closed-ended probit model is 20.20 cents per bucket of improved water services. However, the mean WTP is 15.34 cents per bucket of water from responses to the open-ended contingent valuation survey questions, which is a bit lower than the mean values obtained from the closed-ended probit model estimates. Thus, the finding of the study showed the respondents willingness to pay was in the range of 15.34 - 20.20 cents per bucket for the proposed improvements of water supply services. The similarity of the mean WTP under the open-ended and closed-ended formats indicates the validity and reliability of the contingent valuation outcomes in the empirical analysis. Based on the mean WTP of open-ended format, the total values of water services have been estimated in the following section under the improved scenario. 


\subsubsection{Estimating total willingness to pay and total revenue}

In this section, the total willingness to pay and the total revenue at different prices that households in the three sub-cities of Addis Ababa are willing to pay is computed. The demand curve for improved water service has also been derived.

There were around 432,967 households and 2,211,552 residents in Addis Ababa in 2004 with an average family size of 5.1 (CSA, 2004b). In the study area, the three sub-cities (Bole, Nefas-Silk Lafto and Addis Ketema) were included with a total of 126,108 households and 678,645 residents. The average family size of the study area was found 5.38 , which is similar with the CSA result mentioned above. To make the aggregation, class boundaries for the maximum willingness to pay values have been utilized (Table 4).

From the class boundaries for the willingness to pay amounts, the class marks have been calculated and the results are shown in the second column of Table 4. The third and the fourth columns show the number and the percentage of the sample households whose maximum willingness to pay amounts fall within the given intervals, respectively. 
Kinfe and Berhanu: Valuing water supply service improvements...

\section{Table 4: Total WTP and total revenue from improved water services}

\begin{tabular}{|c|c|c|c|c|c|c|c|c|c|}
\hline $\begin{array}{l}\text { Class bound. } \\
\text { of WTP } \\
\text { (in cents) }\end{array}$ & $\begin{array}{c}\text { Class mark of } \\
\text { WTP } \\
\text { (cents/bucket) }\end{array}$ & $\begin{array}{c}\text { Sample Dist. } \\
\text { of } \\
\text { households }\end{array}$ & $\begin{array}{c}\text { Total No. } \\
\text { HHs }\end{array}$ & & $\begin{array}{l}\text { WTP } \\
\text { nts) }\end{array}$ & $\begin{array}{l}\text { Sample } \\
\text { that amo }\end{array}$ & $\begin{array}{l}0 \text { at least } \\
\text { nulative) }\end{array}$ & $\begin{array}{c}\text { Total HHs WTP } \\
\text { at least that } \\
\text { amount } \\
\text { (Cumulative) }\end{array}$ & $\begin{array}{c}\text { Total } \\
\text { Revenue } \\
\text { (in cents) }\end{array}$ \\
\hline (1) & (2) & $\begin{array}{l}(3) \\
\text { No. }\end{array}$ & $\begin{array}{l}(4) \\
\% \\
\end{array}$ & (5) & (6) & $\begin{array}{r}(7) \\
\text { No. }\end{array}$ & $\begin{array}{l}(8) \\
\% \\
\end{array}$ & (9) & (10) \\
\hline $0-5$ & 3 & 27 & 11.48 & 14,477 & 43,431 & 235 & 100 & 126,108 & 378,324 \\
\hline $6-10$ & 8 & 69 & 29.36 & 37,025 & 296,200 & 208 & 88.51 & 111,618 & 892,944 \\
\hline $11-15$ & 13 & 54 & 22.97 & 28,967 & 376,571 & 139 & 59.14 & 74,580 & 969,540 \\
\hline $16-20$ & 18 & 57 & 24.25 & 30,581 & 550,458 & 85 & 36.17 & 45,613 & 821,034 \\
\hline $21-25$ & 23 & 13 & 5.53 & 6,974 & 160,402 & 28 & 11.91 & 15,019 & 345,437 \\
\hline $26-30$ & 28 & 8 & 3.40 & 4,288 & 120,064 & 15 & 6.38 & 8,046 & 225,288 \\
\hline $31-35^{*}$ & 33 & 0 & 0 & 0 & 0 & 7 & 2.97 & 3,745 & 123,585 \\
\hline $36-40$ & 38 & 3 & 1.27 & 1602 & 60,876 & 7 & 2.97 & 3,745 & 142,310 \\
\hline $41-45^{*}$ & 43 & 0 & 0 & 0 & 0 & 4 & 1.70 & 2,144 & 92,192 \\
\hline $46-50$ & 48 & 4 & 1.74 & 2,194 & 105,312 & 4 & 1.70 & 2,144 & 102,912 \\
\hline Total & & 235 & 100 & 126,108 & $1,713,314$ & & & & \\
\hline
\end{tabular}

Source: Computed based on own survey, 2006

* indicate class boundary of WTP where there is no sample distribution of households 
The total number of households in the three sub-cities of Addis Ababa has been multiplied by the proportion of sample households falling in each boundary to obtain the total number of households whose WTP amount lies in each boundary (column 5 of Table 4). Total willingness to pay (Column 6 of the Table 4) has been obtained by multiplying the mid willingness to pay amount by the total number of households willing to pay that amount.

Summation of the total WTP values in column 6 gives the grand total willingness to pay amount. Thus, 126,108 households in the three sub-cities of Addis Ababa are expected to pay Birr 17,133.14 if every household use only one bucket of water. But survey data on 235 households indicate that the mean water consumption per household per day to be 9 bucket (180 liters). Based on this calculation the total willingness to pay is estimated to be Birr

154,198.26 per day ${ }^{13}$. This is, on average, 13.59 cents per household per bucket if the proposed improvement in water supply services is implemented. This result is almost similar with the average WTP of 15.34 cents per household per bucket from the open-ended format mentioned previously.

Columns 7 and 8 of Table 4 indicate the number and the proportion of sample households willing to pay at least the amount in each boundary and the figures continuously diminish as class mark for WTP amount increases (with the exception of * in Table 4). Similarly, the total number of households who are willing to pay at least the amount in each interval (column 9) falls as the mid willingness to pay amount rises. This relationship can be easily depicted by deriving a demand curve for the improved water supply services.

Total revenue ( $10^{\text {th }}$ Column of the Table) has been obtained by multiplying the mid WTP amount (column 2) by the corresponding total number of households willing to pay at least that amount (column 9). As can be seen from the total revenue columns, total revenue initially increases as payment per bucket increases and reaches a maximum of 969,540 cents per Bucket with the payment of 13 cents per Bucket per household. After that it decreases and reaches a minimum of 102,912 cents per bucket at the highest service charge of 48 cent per bucket per household due to relatively small number of households (only 2,144 ) willing to pay these amounts.

\footnotetext{
${ }^{13}$ The total WTP for 126,128 households is Birr 17, 133.14 assuming every household uses only one bucket. However, sample survey indicated that every household uses 9 bucket per day. Thus, the total WTP for the total households is Birr 17,133.14 $\times 9=$ Birr 154,198.26 per day.
} 
The revenue estimation in this study is very important since it allows water utility to determine how many households can afford the provision of improved water services on charge base. The administrative body can also undertake cost-benefit analysis of a project which is meant to improve the water services in the city. From Table 4 there is a very wide room for cost recovery by improving the existing water supply services in the city.

\subsubsection{Derivation of aggregate demand and estimation of consumer surplus for improved water services}

The aggregate demand for this study has been derived from the above WTP payment scenario. The aggregate demand curve is derived using the mid willingness to pay per bucket along the vertical axis and the number of households' willingness to pay at least that mid value per bucket along the horizontal axis ${ }^{14}$ (Figure 1). The figure shows the aggregate demand curve for the improvements in water supply services using the observations in the study. Any point on the curve shows all the households that prefer the improved water service but do not bid more than the corresponding value on the mid WTP axis.

The demand schedule that has been obtained from our survey is basic information for policy makers. The information helps them to make sound water tariff decisions and investment. The information on the frequency distribution of WTP bids is also useful information in estimating the demand for improved water services in terms of the tariff versus number of households.

As shown in Figure 1, the demand curve is negatively sloped indicating the fall of the demand for improved water supply service as user charges increase, like most other economic goods, other things remaining the same. If water is considered as a free resource to the society, the consumers' surplus would be the total area under the demand curve. The area under the demand curve represents the gross value of consumers' surplus if the tariff rate of the authority is zero. The sum of all the areas under the demand curve $\left(A_{1}-A_{10}\right)$ is 2,021,504 cents per Bucket (Figure 1). This shows the gross consumer surplus is estimated 2,021,504 cents (Birr 20,215.04) if every household is using only one Bucket per day for the improved water services,

\footnotetext{
14 The number of household represents the total quantity demanded for improved water supply measured in bucket, assuming every household uses only one bucket of water per day. For calculation of the total benefit for improved water supply, see Figure 1 and Appendix 4. For related application, see Boardman et al., (2001).
} 
with supply left unrestricted (see Appendix 5). But based on the survey data the gross consumer surplus has been estimated to be 18,193,536 cents (Birr 181,935.36) per day.

The study further analyses the allocation of the total benefits which has been derived from the service charge fees on each household per bucket by improving water supply services. The current tariff rate of AAWSA is 3.50 cents per bucket of water for the lowest consumption block (which is less than $7 \mathrm{~m}^{3} /$ month) and 7.60 cents per bucket for the highest consumption block (for more than $20 \mathrm{~m}^{3} /$ month) that cover only operation and maintenance costs. But the current tariff policy of the water authority could not meet financial sustainability. Thus, if AAWSA proposes a new flat tariff rate for the improved water at 8 cents per bucket (which is well below the mean WTP of own survey) with supply left unrestricted, it may help to cover the authority's costs (operation and maintenance costs plus capital investments). This will help to implement the proposed improved water supply service.

Figure 1: Estimated Demand Curve for Improved Water supply Service in Addis Ababa

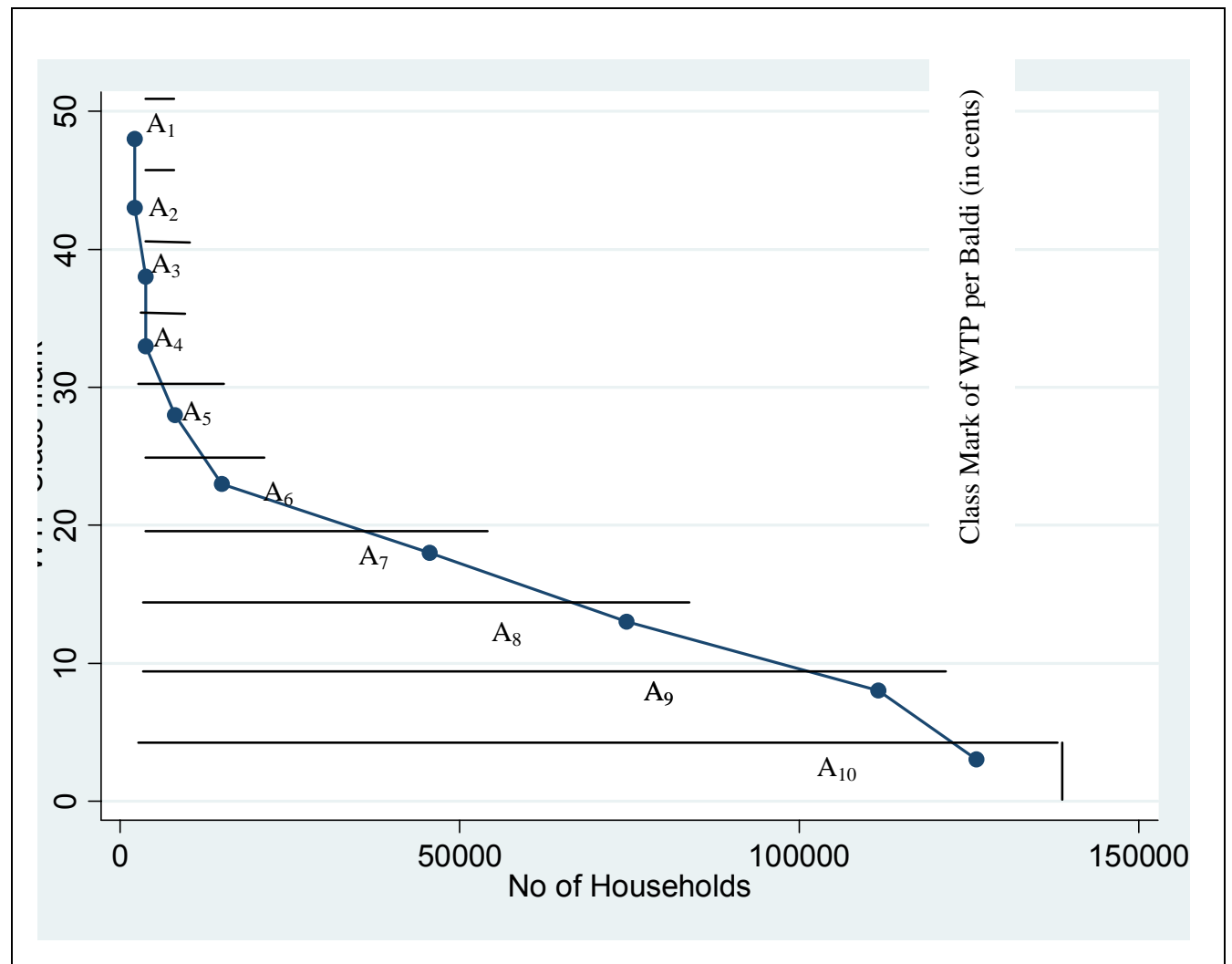

Source: Computation based on own survey, 2006 
The finding indicated that out of the total 126,108 households in the study area, $111,618(88.51 \%)$ of households are assumed willing to pay at least the new proposed tariff rate of 8 cents per bucket for the improvement in water services. In relation to this, a rise in revenue of the authority is anticipated and a large increase in the consumers' surplus, in turn, will help for implementing an improved water project. The allocation of the total benefits of improved water services at the proposed tariff rate can be depicted using Figure 2.

The total benefits of the improved water supply services are the sum of expected revenue of AAWSA, consumer's surplus of the society, and the dead weight loss. If tariff is set for water supply services, the consumers' surplus discussed previously can be minimized by shifting consumer surplus partly to dead weight loss and partly to the revenue of AAWSA.

Figure 2: Estimated total benefit for improved water supply service in Addis Ababa

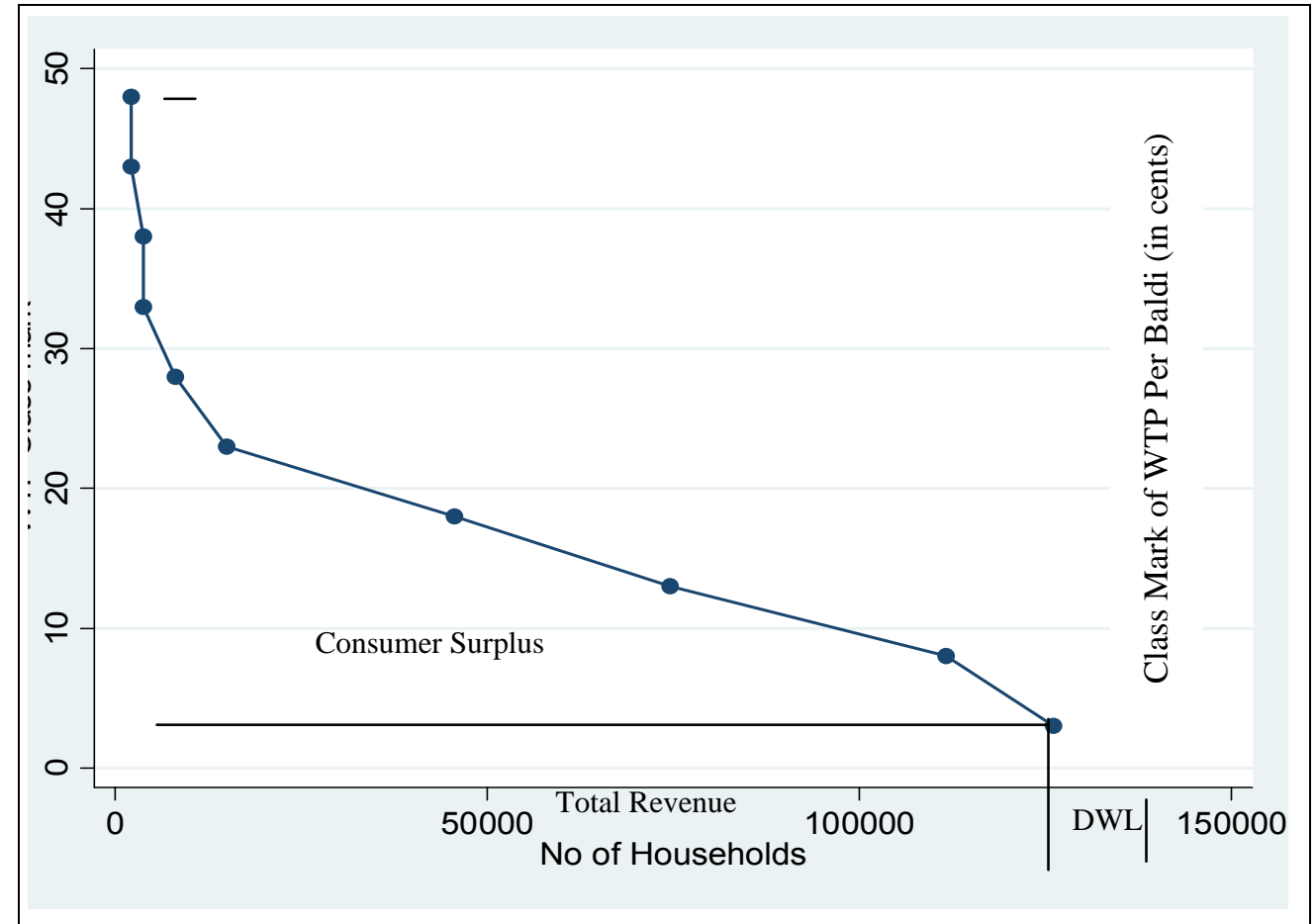

Source: Computation based on own survey, 2006

As indicated in Figure 2, if a new tariff rate of 8 cents per bucket is implemented, the consumers' surplus decreases from $2,021,504$ cents to $1,048,865$ cents per bucket or 
from Birr 181,935.36 to Birr 94,397.85 per day. The rest of the benefit is distributed to AAWSA, 892,944 cents in the form of revenue and 79,695 cents as a dead weight loss (DWL) $)^{15}$ per bucket, which is equivalent to Birr $80,364.96$ in the form of revenue and Birr $7,172.55$ as a dead weight loss per day. The dead weight loss of the study result indicate that only $14,490(11.49 \%)$ out of 126,108 households could not afford for the proposed new tariff rate. The dead weight loss is part of the aggregate benefit of improved water service that belongs neither to the consumer surplus nor revenue to the service delivery authority. However, there is a possibility of cross subsidy to those households who are unable to pay by those who are willing to pay more.

In general, the results of the study in this unit open a room to any interested individuals or groups in the area of improving water supply services in the city. The aggregate WTP amount shows that the authorities could collect sufficient resource for both service modernization and could also reduce existing subsidies.

\section{Summary and conclusion}

In this study we have used a contingent valuation method to analyze determinants of households' WTP, estimate total WTP, and derive aggregate demand and aggregate benefit for improved water supply service. CVM helps to estimate the value that households in Addis Ababa attach to the proposed improvement in water supply service. For this purpose, a total of two hundred forty (240) households were interviewed after stratifying sub-cities and kebeles based on economic standard and water supply availability, respectively. A closed-ended with open-ended follow-up elicitation technique was used.

The empirical analysis we conducted and its findings show that controlling for the other variables in the model, income of the household, sex of the respondent, education dummies (both secondary and tertiary education), households year of stay, households not using tank as a storage, wealth of a household, employment status of the respondent, households' satisfaction with the existing service, and location of the study site (Addis Ketema) affect the willingness to pay for improved water service positively. On the other hand, family size affects the willingness to pay negatively.

The total willingness to pay amount from the total of 126,108 households in the study area of Addis Ababa is Birr 17,133.14 per bucket or Birr 154,198.26 per day at different service fees. The maximum total revenue that can be collected per bucket is

${ }^{15}$ DWL- measures the value to the consumer of the lost output (Varian, 1992). 
969,540 cents when a service fee of 13 cents per bucket is charged. The area under the demand curve represents the gross value of consumers' surplus which is Birr 20,215.04 per bucket if water is considered as a free good (zero tariff rates for water). Based on the survey data of the mean water consumption per household per day the gross consumer surplus is estimated to be Birr 181,935.36 per day. But water is an economic good and if a new tariff rate of the authority is supposed to be 8 cents per bucket the consumers' surplus will be reduced to Birr $94,397.85$ per day. The rest of the benefit is distributed to the water authority Birr 80,364.96 in the form of revenue and Birr 7, 172.55 is a dead weight loss per day. This proposed new tariff rate can help the water authority to implement the proposed improvement of water supply service.

The mean willingness to pay value is 15.34 and 20.20 cents per bucket for the improved water supply service as calculated from the tobit and probit model, respectively. Hence, the mean willingness to pay value ranges between 15.34 and 20.20 cents. The similarity of the mean WTP under tobit and probit models indicate the validity and reliability of the contingent valuation outcomes in empirical analysis.

It may be safely recommended from this study that income and willingness to pay for the proposed improvement in water supply service is positively related, development policies should target at increasing income per household that address the low income members of the society. Income source diversification strategies and expansion of small scale enterprises which can employ households in the lower income strata are the possible areas of intervention

This study, however, lack the comprehensiveness as it has limited water supply service for domestic purpose only. Thus, further study needs to incorporate water supply for industrial, institutional and commercial purpose to have more real image on water supply service in Addis Ababa. 


\section{References}

Abdella Said Shah. 2003. Value of Improvements in Water Supply Reliability in Zanzibar Town. Unpublished M Sc Thesis, Yale University, School of Forestry and Environmental Studies.

Alebel Bayrau. 2004. Affordability and Willingness to Pay for Improved Water Supply in Urban Areas of Ethiopia: the case of Nazareth Town

Altaf, A., Harron, J. and Whittington, D. 1992. Willingness to Pay for Water in Rural Punjab, Pakistan. World Bank Water and Sanitation Program, Washington, D.C.

Boardman, A. E., Greenberg, Vining, Weimer. 2001. Cost-Benefit Analysis. $2^{\text {nd }}$ ed., Prentice Hall, Inc., Upper Saddle River, New Jersey.

Borgoyary M. 2002. Valuation of Water : Options for Sustainable Development in Developing Countries.

BoFED. 2004. A Conceptual Back-Ground for Policy on Private-Public Partnership in the Provision of Municipal Services in Addis Ababa, Unpublished, Addis Ababa City Government.

Callan, Scott J. and Thomas Janet M. 1996. Environmental Economics and Management: Theory, Policy and Applications. South Western College Publishing, $1^{\text {st }}$ ed. Chicago, Irwin

Carlsson, F., H. Gunaltilake and Kohlin G. 2002. Willingness to Pay for Solid Waste Management, Work in Progress.

Carson, R. 2000. Contingent Valuation: A User's Guide. Department of Economics, University of California, San Diego, California.

Carson R. T., Flores N. E. and Meade N. F. 1996. Contingent Valuation: Controversies and Evidence, mimeo. An earlier version presented at the Western Economics Association Meeting.

Carson, R. T. and Mitchell, R. C. 1987. Economic Value of Reliable Water Supplies for Residential Water Users in the State Water Project Service Area. Metropolitan Water District of Southern California. Palo Alto, QED Research, Inc.

CSA. 2004a. Information on Urban Economic Establishment Census, Unpublished data. Addis Ababa.

2004b. Welfare Monitoring Survey, Analytical Report. 339-A Statistical Bulletin 339-A Addis Ababa

Davis, Robert K. 1963. The Value of Outdoor Recreation: An Economic Study of Marine Woods, Ph. D. Dissertation, Harvard University.

Dunfa Lemesa. 1998. The Willingness to Pay of Rural Households for Improved Rural Water Provision in Ada'a-Liben District, Central Ethiopia. Unpublished MSc. Thesis, Department of Economics, School of Graduate Studies, Addis Ababa University.

Fissiha Aberra. 1997. Estimating Willingness to Pay for Water: A Contingent Valuation Study on Meki Town, Ethiopia. Unpublished MSc. Thesis. Department of Economics, Addis Ababa University.

Genanew Bekele. 1999. Analysis of Determinants of Households' Willingness to Pay and Demand for Improved Water Services: A Contingent Valuation Study in Harar Town, 
Ethiopia. Unpublished MSc. Thesis, Department of Economics, Addis Ababa University.

Gleick, P. H. 2001. The World's Water 2000-2001. The Biennial Report of Freshwater Resources. Pacific Institute for Studies in Development Environment and Security. Island Press.

Green, D., K. E. Jacowitz, D. Kahneman and D. McFadden. 1995. Referendum Contingent Valuation, Anchoring, and Willingness to Pay for Public Goods, A Paper Presented at the August 1995 World Congress of the Econometric Society, Tokyo.

Greene, W. H. 1997. Econometric Analysis. $3^{\text {rd }}$ ed., New Jersey: Prentice- Hall, Inc.

Habb, T. C., and McConnell, K. E. 2002. Valuing Environmental and Natural Resource: The Econometrics of Non-Market Valuation. New Horizons in Environmental Economics, Edward Elgar.

Hanemann, M. W. 1984. Welfare Evaluations in Contingent Valuation Experiments with Discrete Responses, American Journal of Agricultural Economics, 66, 332-41 1994. Contingent Valuation and Economics; Working Paper No. 697, Development of Agricultural and Resource Economics and Policy, Division of Agriculture and Natural Resources, University of California, Berkeley.

1996. Theory Versus Data in the Contingent Valuation Debate; in D. J. Bjornstad and J. R. Kahn, eds., The Contingent Valuation of Environmental Resources: Methodological Issue and Research Needs. Cheltenham: Edward Elgar

Hanemann, M. W., Loomis, J. and Kanninen, B. 1991. Statistical Efficiency of Double-Bounded Dichotomous Choice Contingent Valuation. American Journal of Agricultural Economics. 73(4): 1255-1263.

Maddala, G. S. 2002. Introduction to Econometrics. $3^{\text {nd }}$ ed., John Wiley and Sons Ltd. Singapore.

MoFED and UNDP. 2005. The Federal Democratic Republic of Ethiopia. Ministry of Finance and Economic Development and UNDP. Ethiopia-MDGs Needs Assessment Water Supply. Final Report. Tropics Consulting Engineers plc.

MoWR. 2003.The Federal democratic Republic of Ethiopia. Environmental Support Project Component 3. National Water Supply and Sanitation, Master Plan Frame Work. Part A.

Mitchell, R. C. and Carson, R. T. 1989. Using Surveys to Value Public Goods: The Contingent Valuation Method. Resources for the Future, Washington, D.C.

Montes de Oca G.S., Bateman J., R. Tinch and Moffatt P. G. 2003. Assessing the Willingness to Pay for Maintained and Improved Water Supplies in Mexico City. CSERGE Working Paper ECM 03-11. Available from:i.bateman@uea.ac,uk

Shiferaw B., H. A. Freeman and S. Navrud. 2005. Valuation Methods and Approaches for Assessing Natural Resource Management Impacts, in Shiferaw B., H. A. Freeman and S. M. Swinton (eds.) Natural Resources Management in Agriculture. Methods for Assessing Economic and Environmental Impacts. Michigan State University, East Lansing, Michigan, USA, CAPI Publishing.

Varian, Hal R. 1992 .Microeconomic Analysis, $3^{\text {rd }}$ ed. University of Michigan.

Water Aid. 2006. Bridging the Gap: Citizens' Action for accountability in Water and Sanitation, Durham Street, London 
WEDC. 1999. Integrated Development for Water Supply and Sanitation, $25^{\text {th }}$ conference, Addis Ababa.

Whittington D. 1998. Administering Contingent Valuation Surveys in Developing Countries. World Development. Vol. 26, No. 1, 21-30.

Whittington, D., J. Briscoe, X. Mu and W. Barron. 1990. Estimating the Willingness to Pay for Water Services in Developing Countries: A Case Study of the Use of Contingent Valuation Surveys in Southern Haiti. Economic Development and Cultural Change, 38(2): 293-311

Zerihun, Amdemariam. 2005. Addis Ababa Water and Sewerage Authority, Water Supply Situation Map. Engineering Services Department, GIS unit, Unpublished Map, Addis Ababa. 


\section{Appendix 1: Willingness to pay for Improved Water Supply Service}

For all scenarios by an improved provision of water, we mean:

-Good quality of water which is safe for health is provided.

- Good quantity of water is available for 24 hours per day, throughout the year.

- Collection of water need not take much of your time and effort.

$C_{1}$. What is the main source of water for this household for domestic purpose?
a) Private piped water
b) Shared piped water
c) Others

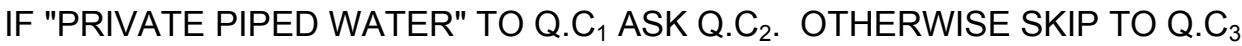

\section{SCENARIO I: Willingness to Pay for Improved Water Supply Service}

(For Households with Private Pipe Connection)

$C_{2}$.Are you willing to pay any amount to the improved water provision?
1. yes $\mathbf{G O}$ TO Q. $\mathbf{C}_{2 \mathrm{a}}(\mathbf{C} 2 \mathrm{a}-\mathbf{C} 2 \mathbf{b})$

2. No SKIP TO Q. $C_{5}\left(C_{5}\right.$ only)

$C_{2 a}$. If "yes" suppose that AAWSA presented the improved Water service, would you be willing to

pay ___ cents per bucket to obtain improved water from this new scheme?
1. yes $\mathbf{G O}$ TO Q.C.

2.No GO TO Q.C $2 b$

$C_{2 b}$. What is the maximum you could pay for one bucket of water for the improved water scheme? cents per bucket.

IF "b" OR "c" TO Q. C 1 ASK Q. $C_{3}$ 


\section{SCENARIO II: Willingness to Pay for Improved Private Pipe Connection (For Households with No Private Pipe Connection)}

Assume also that you have private water connection together with the improved water supply scheme. Notice also that you may not be required to pay initially the costs of connection to the new scheme.

Instead, the WASA (water and sewerage authority) will cover the costs with insignificant increase in the tariff rate.

$C_{3 .}$ Are you willing to pay any amount to have private pipe connection with the improved water provision?

$$
\text { 1. yes } \mathbf{G O} \text { TO Q. } \mathbf{C}_{3 \mathrm{a}}\left(\mathbf{C}_{3 \mathrm{a}}-\mathbf{C}_{3 \mathrm{~b}}\right)
$$

2. No SKIP TO Q. $C_{4}\left(C_{4}-C_{4 b}\right)$

$C_{3 a}$.If "yes" suppose the authority presented the improved water service with private pipe connection,

would you be willing to pay__ cents per bucket to connect improved pipe water from

$$
\begin{aligned}
& \text { this new scheme? } \\
& \text { 1.Yes GO TO Q.C } \mathbf{C}_{3 \mathrm{~b}} \\
& \text { 2.No GO TO Q.C } 3 \mathrm{~b}
\end{aligned}
$$

$C_{3 b}$. What is the maximum you could pay for one bucket of water for this improved pipe

water scheme? cents per bucket. 


\section{SCENARIO III: Willingness to Pay for Improved Public Tap Service (For Households with No Private Pipe Connection)}

$\mathrm{C}_{4}$.Are you interested in the provision of public tap?

1. Yes GO TO Q. $\mathbf{C}_{4 \mathrm{a}}\left(\mathbf{C}_{4 \mathrm{a}}-\mathbf{C}_{4 \mathrm{~b}}\right)$

2. No GO TO Q. $C_{5}\left(C_{5}\right.$ only)

$C_{4 a}$.If "yes" suppose that a new scheme of improved water system will be provided using a public tap

as near as possible to your home. You will not pay initially the costs of connection to the new

scheme but the authority will cover the costs with insignificant increase in the tariff rate. Would

you be willing to pay cents per bucket of water for such public tap?

1. yes $\mathbf{G O}$ TO Q. $\mathbf{C}_{4 b}$

\section{No GO TO Q. $\mathbf{C}_{4 \mathrm{~b}}$}

$C_{4 b}$. What is the maximum you could pay for one bucket of water for this improved water

scheme? cents per bucket.

$C_{5}$. Are you totally not willing to pay because you believe that:
a) The existing system is satisfactory
b) You can't afford the new scheme
c) The government should pay
d) Other reasons (specify) 


\section{Appendix 2: Description of Explanatory Variables}

\begin{tabular}{|c|c|}
\hline $\begin{array}{c}\text { Dummy } \\
\text { Variables }\end{array}$ & Explanatory Variables \\
\hline WEAH & $\begin{array}{l}\text { Ownership of house- is a proxy for wealth. Wealthy households are more willing } \\
\text { to pay and prefer to have a private connection to the improved water service. It } \\
\text { is a dummy variable, } 1 \text { if the house is owned by the household, } 0 \text { otherwise (that } \\
\text { is, if rented from individuals, kebeles or public agency. Thus a positive sign is } \\
\text { expected. }\end{array}$ \\
\hline SEXR & $\begin{array}{l}\text { Sex of Respondent -fetching water primarily depends on women in most } \\
\text { developing countries. Thus, it is hypothesized that women are more likely to pay } \\
\text { for improved water supply than men. It is a dummy variable, } 1 \text { if the respondent } \\
\text { is female, } 0 \text { other wise. }\end{array}$ \\
\hline EMPR & $\begin{array}{l}\text { Employment status of Respondent- This is a dummy variable, taking } 1 \text { if the } \\
\text { respondent is employed in a government or private organization, NGO's, owns } \\
\text { a business, and other related areas ; } 0 \text { otherwise (that is if not employed). The } \\
\text { employed respondents are expected to be more willing to pay than their } \\
\text { unemployed counter parts. This is because the exposure (the state of having } \\
\text { the true facts) of those who are working in different sectors to the improved } \\
\text { water service is more than the other group. Thus we expect a positive sign. }\end{array}$ \\
\hline ATTR & $\begin{array}{l}\text { Attitude of Respondent about the Responsibility of Water Supply- It is a dummy } \\
\text { variable, and takes } 1 \text { if the respondent says the government should administer, } \\
0 \text { otherwise. We expect a negative sign. If the respondent says the government } \\
\text { should administer (manage) the water service, it might be expected that the } \\
\text { government will provide the service at lower price and thus less WTP. }\end{array}$ \\
\hline LOC & $\begin{array}{l}\text { Location of the Study Sites-LOC }{ }_{B o} \text { is dummy variable taking } 1 \text { if it is Bole sub- } \\
\text { city, } 0 \text { otherwise. } \text { LOC }_{A K} \text { is dummy variable taking } 1 \text { if it is Addis-Ketema sub- } \\
\text { city, } 0 \text { otherwise. It is expected that households in a sub-city with more problem } \\
\text { of water supply are willing to pay more for improved water supply scheme than } \\
\text { sub-city with less problem of water supply service. }\end{array}$ \\
\hline EDUR & $\begin{array}{l}\text { Education Level of the Respondent -WTP for improved water service is } \\
\text { expected to have a positive relation with the level of education, since } \\
\text { respondents with higher education have more awareness of the value of water } \\
\text { services. EDUC }{ }_{1} \text { is a dummy variable taking } 1 \text { if the respondent's educational } \\
\text { level is primary education; } 0 \text { otherwise. EDUC }{ }_{2} \text { is a dummy variable taking } 1 \text { if } \\
\text { the respondent's educational level is secondary education; } 0 \text { otherwise. EDUC }{ }_{3} \\
\text { is a dummy variable taking } 1 \text { if the respondent's educational level is tertiary } \\
\text { education; } 0 \text { otherwise. }\end{array}$ \\
\hline TANK & $\begin{array}{l}\text { Household use of Tanks as Storage for Water -It is assumed that households } \\
\text { with no tank as a storage for water may be willing to pay more for improved } \\
\text { water services than households who use tank for water storage, since the } \\
\text { severity of water supply disturbance is higher for the former. A dummy of } 1 \text { is } \\
\text { specified for household with no tank as a storage for water; } 0 \text { otherwise. The } \\
\text { coefficient is expected a positive sign. }\end{array}$ \\
\hline STAT & $\begin{array}{l}\text { Status of the Respondent- This variable helps to examine whether the } \\
\text { representative of the household gives similar opinion with that of the head of the } \\
\text { household on willingness to pay or not. It is a dummy variable taking } 1 \text { if the }\end{array}$ \\
\hline
\end{tabular}


respondent is the head of household; 0 otherwise. We expect a negative sign since the head of the household is concerned more about the management of his /her limited finance that s/he could allocate, based on prioritized activities. Respondent's Information about Tariff Increment on Domestic Water Consumption- Dummy variable 1 if the respondent has the information, 0 otherwise. We expect a positive sign. Households who know tariff increment are

INFO more responsible about cost sharing than their counter parts. Hence, respondents that have the information regarding tariff increment on domestic water consumption are more willing to pay for improved water service than respondents with no information.

Level of Satisfaction of the Household with the Existing Water Services- dummy variable 1 if the household is not satisfied with the existing water service; 0 other

SATI wise. It is expected with a positive sign. This is since households that are not satisfied with the existing water services show grater preference for improved services and more willing to pay to connect for improved water service.

\section{Continuous} variables

Total monthly income of the household. The monthly income of the household includes the income of the head and all other members of the household from different sources. Households with higher income have a greater ability to pay

INCH and have a grater preference for an improved water services. This is based on previous empirical studies and economic theory that shows quantity demanded and income are positively related for normal goods. So we expect a positive coefficient. We are looking at the household's disposable income (in birr). Family Size of the Household-two rationales are forwarded. The first indicate that as family size is higher, there will be a higher need for water in the family and hence more preference for an improved water provision, and WTP is higher.

FAMS The second indicate that for large family size it is expected to increase their water consumption for improved water service which could discourage the family due to high bill charge services and hence willing to pay less for the proposed improvements than small size households. Thus we can not determine its sign a priori.

Age of Respondent- continuous variable in number of years. Older people who used to live with free water supply or less prices, may be reluctant to prefer new

AGER improved services and could be less willing to pay for it. Thus, a negative relationship is expected between the age of a respondent and WTP for new improved scheme.

Initial Bid- this will help to examine whether the initial bid do have an impact on

IB the respondent's WTP for improved water services or not. It is to be tested for initial bid bias.

Household Year of Stay in the House -continuous variable in a number of years. It is expected to be a positive coefficient. Those households who have stayed in the STAY house for long year are mostly in the older quarter of the city where there is more serious problem of water supply service and thus are willing to pay more for improved water services than those households who have stayed short in the house. 
Appendix 3: Summary of Descriptive Statistics of Variables

\begin{tabular}{|c|c|c|c|c|c|}
\hline Dummy Variables & Observ. & Mean & Std.Dev & Min & Max \\
\hline $\begin{array}{l}\text { Primary education of the respondents } \\
\left(E^{\prime} C_{1}\right)\end{array}$ & 235 & .24 & .43 & 0 & 1 \\
\hline $\begin{array}{l}\text { Secondary education of the } \\
\text { respondents }\left(E \operatorname{EUC}_{2}\right)\end{array}$ & 235 & .34 & .48 & 0 & 1 \\
\hline $\begin{array}{l}\text { Tertiary education of the } \\
\text { respondents }\left(\mathrm{EDUC}_{3}\right)\end{array}$ & 235 & .19 & .39 & 0 & 1 \\
\hline Information about tariff (INFO) & 235 & .77 & .42 & 0 & 1 \\
\hline Status of the respondents (STAT) & 235 & .59 & .49 & 0 & 1 \\
\hline Wealth of the households (WEAH) & 235 & .58 & .49 & 0 & 1 \\
\hline $\begin{array}{l}\text { Employment status of the respondents } \\
\text { (EMPR) }\end{array}$ & 235 & .37 & .48 & 0 & 1 \\
\hline Attitude of the respondent (ATTR) & 235 & .78 & .41 & 0 & 1 \\
\hline Yes/no $(\mathrm{Y} / \mathrm{N})$ to initial bid & 235 & .85 & .35 & 0 & 1 \\
\hline Sex of respondents (SEXR) & 235 & .71 & .45 & 0 & 1 \\
\hline $\begin{array}{l}\text { Households use of tank as a storage of } \\
\text { water (TANK) }\end{array}$ & 235 & .69 & .46 & 0 & 1 \\
\hline Location of the study site Bole $\left(\mathrm{LOC}_{\mathrm{BO}}\right)$ & 235 & .31 & .46 & 0 & 1 \\
\hline $\begin{array}{l}\text { Location of the study site Addis-Ketema } \\
\left(\mathrm{LOC}_{\mathrm{AK}}\right)\end{array}$ & 235 & .34 & .47 & 0 & 1 \\
\hline $\begin{array}{l}\text { Location of the study site N. Silk Lafto } \\
\left(\mathrm{LOC}_{\mathrm{NL}}\right)\end{array}$ & 235 & 35 & .48 & 0 & 1 \\
\hline $\begin{array}{l}\text { Level of satisfaction to the existing water } \\
\text { services (SATI) }\end{array}$ & 235 & .84 & .37 & 0 & 1 \\
\hline \multicolumn{6}{|l|}{ Continuous Variables } \\
\hline Income of the households (INCH) & 235 & 1339.32 & 1481.21 & 110 & 8500 \\
\hline maximum WTP & 235 & 15.34 & 8.53 & 0 & 50 \\
\hline Initial bid (IB) & 235 & 9.98 & 4.15 & 5 & 15 \\
\hline Age of respondents (AGER) & 235 & 34.98 & 14.89 & 17 & 85 \\
\hline Family size of the households (FAMS) & 235 & 4.79 & 1.89 & 1 & 10 \\
\hline $\begin{array}{l}\text { Households year of stay in the house } \\
\text { (STAY) }\end{array}$ & 235 & 19.95 & 12.57 & .75 & 60 \\
\hline
\end{tabular}

Source: Own survey result, 2006 


\section{Appendix 4: Test of Heteroscedasticity}

One of the important methods used to test the existence of hetroscedasticity in Tobit model is the log -likelihood ratio test (LR) test. The LR statistics of testing the null hypothesis of homoscedasticity assumption is obtained by

$$
\begin{aligned}
\lambda_{L R}= & 2[\log L u-L o g L r] ; \text { Where } \\
& \log L u \text { is the value of unrestricted log-likelihood function and } \\
& \log L r \text { is the value of restricted log -likelihood function }
\end{aligned}
$$

$\lambda_{L R}$ has a $X^{2}(n)$ distribution with $n$ degrees of freedom where $n$ is the number of explanatory variables. If the data do not support the null hypothesis (homoscedasticity assumption), then the value of the test-statistic becomes large and null hypothesis is rejected; i.e, if $\lambda_{L R} \geq X^{2}(n)$. The result of the test for the model is shown below.

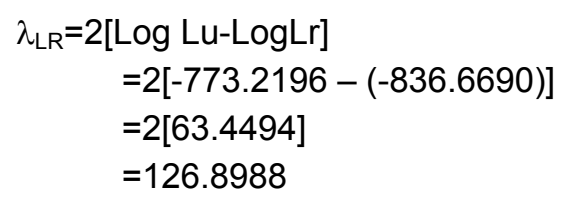

The critical value of the chi-square at 18 degree of freedom is 28.87 at $95 \%$ level. Comparison of the result (test statistic) with critical table value shows that the test statistic (computed value) is found to be larger than the critical table value. This implies that the null hypothesis of homoscedasticity is rejected, i.e. hetroscedasticity is the problem for the model. But this hetroscedasticity problem has been corrected using LIMDEP version 7.0 software. 
Appendix 5: Estimating consumer's surplus using Figure 1

\begin{tabular}{|c|l|c|}
\hline Area & \multicolumn{1}{|c|}{ Computation } & Value of consumer's surplus (in cents) \\
\hline$A_{1}$ & $2144 \times 5$ & 10,720 \\
\hline$A_{2}$ & $(2144 \times 5)+1 / 2(1601 \times 5)$ & $14,722.5$ \\
\hline$A_{3}$ & $3745 \times 5$ & 18,725 \\
\hline$A_{4}$ & $(3745 \times 5)+1 / 2(4301 \times 5)$ & $29,477.5$ \\
\hline$A_{5}$ & $8046 \times 5+1 / 2(6973 \times 5)$ & $57,662.5$ \\
\hline$A_{6}$ & $15019 \times 5+1 / 2(30594 \times 5)$ & 151,580 \\
\hline$A_{7}$ & $(45613 \times 5)+1 / 2(28967 \times 5)$ & $300,482.5$ \\
\hline$A_{8}$ & $(74580 \times 5)+1 / 2(37038 \times 5)$ & 465,495 \\
\hline$A_{9}$ & $(111618 \times 5)+1 / 2(14490 \times 5)$ & 594,315 \\
\hline$A_{10}$ & $126108 \times 3$ & 378,324 \\
\hline Total & & $\mathbf{2 , 0 2 1 , 5 0 4}$ \\
\hline
\end{tabular}

Source: Computed based on own survey, 2006 
Kinfe and Berhanu: Valuing water supply service improvements... 